\title{
Les Gommes, de Alain Robbe-Grillet: vozes de coexistência
}

\author{
Les Gommes, by Alain Robbe-Grillet: voices of coexistence
}

\author{
IURI ALMEIDA MÜLLER* \\ Pontifícia Universidade Católica do Rio Grande do Sul, Porto Alegre, RS, Brasil
}

Resumo: Espécie de marco inaugural do chamado novo romance francês, Les Gommes, de Alain Robbe-Grillet, também antecipa as questões que interessariam o autor durante toda a sua obra: o problema da linearidade no romance, a presença de distintos planos na narrativa, a descrição e a visão como maneira de enxergar e narrar um mundo recém-tocado pela perplexidade. Há, nas vozes de Les Gommes, um novo tratamento do tempo na obra literária e a constituição de um romance que, a todo momento, se abre a diversas possibilidades de se contar uma história. Aqui, Les Gommes é lido como romance policial ao revés, exemplar que, simultaneamente, nega e dignifica o gênero.

Palavras-chave: Alain Robbe-Grillet; novo romance francês; tempo e narrativa; fenomenologia.

\begin{abstract}
A kind of inaugural frame of the new French novel, Les Gommes, by Alain Robber-Grillet, also anticipates the questions that would interest the author during all his work: the problem of linearity in the novel, the presence of distinct layers in narrative, the description and the vision as a way to watch and tell a world just impacted by perplexity. There is, on the voices of Les Gommes, a new treatment of time in literary work and the constitution of a novel that, all the time, opens to many possibilities of telling a story. Here, Les Gommes is read as an upside-down crime fiction, which simultaneously denies and dignifies the genre.
\end{abstract}

Keywords: Alain Robbe-Grillet, new French novel, time and narrative; phenomenology.

\footnotetext{
* Mestre em Letras - Escrita Criativa pela Pontifícia Universidade Católica do Rio Grande do Sul (PUCRS). Atualmente, cursa
} o Doutorado em Letras - Teoria da Literatura na PUCRS. 


\section{Notas sobre um romance}

O inspetor Wallas é enviado para uma cidade sem nome para que auxilie num estranho caso policial em que as partes envolvidas parecem cada vez mais distantes de um desfecho. Se Les Gommes (1953), o primeiro romance publicado pelo escritor francês Alain Robbe-Grillet, pode, de fato, ter a trama definida pelo período acima, a síntese extrema não alcança, nem de longe, a complexidade do intento literário do autor. Espécie de marco inaugural do que é chamado de novo romance francês, denominação empregada a um momento literário que reuniu autores que, a partir de distintas formas, questionavam o romance tradicional e a sua técnica, Les Gommes também antecipa as questões que interessariam Robbe-Grillet durante toda a sua obra: o problema da linearidade no romance, a presença de distintos planos na narrativa, a descrição e a visão como maneira de enxergar e narrar um mundo recém-tocado pela perplexidade e, ainda, e neste caso justamente os dois pontos que mais interessam a este trabalho, um novo tratamento do tempo na obra literária e a constituição de um romance que, a todo momento, se abre a diversas possibilidades e vozes para se contar uma história.

Les Gommes, romance policial ao revés, exemplar que, simultaneamente, nega e dignifica o gênero, parte de um crime e da impossibilidade da sua resolução para criar uma intrincada rede de relações possíveis e de fragmentos que nem sempre se completam. Trata-se, antes que nada, de um romance de uma busca: a busca pelo suposto assassino de Daniel Dupont, professor universitário que, no entardecer de uma terça-feira, recebe um tiro no escritório de sua casa e que acaba por simular a própria morte - disfarce, talvez, para driblar os atos de uma organização terrorista que, durante uma semana, leva a cabo um assassinato por dia em distintas cidades do país. A busca por um assassino que, de momento, não existe, põe em movimento o passo de estranhos personagens por uma cidade cortada por córregos, pequenas pontes levadiças, boulevards circulares e amplas praças; uma cidade jamais nomeada, mas sobre a qual o leitor pode até mesmo traçar suas linhas, pensar uma geografia própria, imaginar seu mapa.

Por ali, caminharão Wallas, inspetor que, em alguns momentos, anda a esmo, exasperado pela impossibilidade de encontrar pistas verdadeiras, sinais concretos que possam levá-lo às pegadas do criminoso e à compreensão dos fatos; Garinati, torpe assassino que não lê o tempo corretamente, ou ignora as variáveis do acaso, e acaba por perder o momento exato de disparar uma bala; o doutor Juard, médico ambíguo, que empresta seu nome e sua clínica ao plano de Dupont e que parece andar tão só pelas sombras; a velha Anna, governanta da casa de Dupont, dona de um discurso à primeira vista catatônico; bem como seres anônimos que se movem pelas mesmas redes (pela Rua dos Agrimensores, palco do quase-crime e das investigações), como o proprietário do Café dos Aliados, o homem de sobretudo que tanto se parece com Wallas, as vendedoras do comércio local, os operários que, no começo da manhã, rumam para as fábricas de bicicletas, costeando os canais. Aqui, Robbe-Grillet prefere a ambiguidade dos nomes que se misturam, dos diálogos que se interrompem, dos comportamentos oscilantes, ao passo que deixa para trás a planura dos "personagens-tipo", paradigma 
de cem anos antes e que permanecia intacto em boa parte da produção literária francesa e europeia do século XX.

Em Les Gommes, ainda que o leitor possa encontrar o cenário e os personagens de um romance policial por começar, a intenção com estes seres que espreitam e com esta geografia propícia ao enigma é outra; aqui, a trama, os nomes, os espaços construídos na narrativa, prestam-se antes à experimentação, ao encadeamento das possibilidades, a um narrar que em algum momento se aproxima da tentativa infinita, da multiplicidade de vozes e da exaustão. Escreve Leyla Perrone-Moisés sobre as características comuns nas obras do novo romance francês que

a insegurança, fruto da incapacidade de conhecer qualquer coisa em definitivo, faz que o homem tome frequentemente nesses livros o papel de espião, que espreita por janelas ou portas, que persegue outros homens por ruas labirínticas ou por mudos corredores. Daí o caráter aparentemente policial de muitas dessas obras. Na verdade, o espião maior, que é o romancista, não procurar saber quem é o criminoso pois se nem ao menos pode afirmar que houve crime - mas o que lhe interessa é explorar as infinitas possibilidades do acontecimento, como faz o detetive do romance policial, mas por outros motivos (1966, p. 28).

Tal afirmação, que de fato é competente para expressar uma característica de conjunto, sem dúvidas se aproxima do exemplo individual de Les Gommes, traduzido em Portugal como Entre dois tiros. As infinitas possibilidades do acontecimento a que se refere PerroneMoisés encontram, em Robbe-Grillet, a situação da descrição e da repetição, e por vezes das descrições repetidas - um mesmo momento da narrativa, em Les Gommes, volta a ser contado páginas depois, às vezes com modificações sutis (como que vista de outro ângulo, como se a câmera que focaliza o instante tivesse se movimentado), em outras com a alteração de quem observa, do sujeito por trás da visão, e, por fim, com um punhado de detalhes antes ignorados. $\mathrm{O}$ instante é o mesmo e não é: qualquer mudança, mínima que seja, no tempo ou no espaço, no olhar ou no movimento, acaba por criar, na literatura de Robbe-Grillet, um instante renovado, uma partícula de acontecimento que recebe outra cor, outro brilho, outra voz. Tal repetição pode ser encontrada, diversas vezes, na forma com que o narrador descreve os objetos que retornam à narrativa.

Um cubo multifacetado, espécie de peso de papel, que repousa na mesa de trabalho de Daniel Dupont; os diferentes tipos de borracha que o inspetor Wallas procura (e as compra) no comércio da cidade, e que sente na mão, e observa os seus lados, para sempre perceber que não era a borracha ideal; o quadro situado na metade da escadaria do pavilhão onde vive Dupont, e que retrata uma torre num primeiro plano, raios ao fundo, e dois seres humanos adormecidos (ou fulminados?) ao pé da edificação. Esses são alguns dos objetos cuja incidência se repete em diversos momentos da leitura de Les Gommes, e que, através da descrição pormenorizada, oscilante, reiterada e nunca igual, acaba por adquirir vivacidade, dividir as atenções e os esforços de narração com o que se relaciona mais diretamente com os personagens e os acontecimentos. Aqui, e eis outra constante do novo romance francês, as coisas, os objetos, parecem abandonar uma opacidade que, 
talvez, tenha sido um destino imposto pelo homem, e não uma condição natural de existência, no mundo e na literatura. Para Leyla Perrone-Moisés,

em alguns dos novos-romancistas, [o objeto] tem função semelhante à que tinha nos romances realistas e naturalistas: o behaviorismo, tendência psicológica em que se apoiam esses romancistas, faz com que o homem seja visto ligado de modo indissolúvel ao seu campo de ação, isto é, aos objetos. Mas, em outros, seu valor não será social nem psicológico: ele rivalizará com o homem, em importância. No romance de alguns, sua importância será a mesma que a do homem, já que o homem é visto como um objeto entre outros (...) (1966, p. 24).

$\mathrm{Na}$ introdução à edição portuguesa, Urbano Tavares Rodrigues escreve que, com Robbe-Grillet, "a decadência do antropocentrismo chega, aridamente, ao encadeamento dos acontecimentos fora de lógica", isto é, "o seu romance brota das coisas, não das determinações humanas mas dos seres inanimados e insignificativos que rodeiam o homem" (s.d., p. 08). Os objetos que retornam sem cessar, como que manejados por uma obsessão exterior, os acontecimentos circulares, mas nunca definitivos, a ambiguidade dos personagens falantes, a duplicidade dos seus gestos: tais fatores não podem ser lidos, aqui, como características isoladas, mas como linhas de uma mesma proposta literária, proposta que acompanha, página a página, este romance. Essa proposta encontra escopo, como não poderia ser diferente, numa visão de mundo que é ainda mais ampla que a literatura, e que se aproxima muito do pensamento fenomenológico.

Se, como escreveu Maurice MerleauPonty em Fenomenologia da percepção, a fenomenologia é a busca das essências, o retorno a um olhar que se pretende despido dos juízos e das significações antecipadas, esse movimento encontra eco na intenção literária de escritores como Alain Robbe-Grillet e Michel Butor, entre outros novos romancistas. MerleauPonty, ademais, nunca distanciou a filosofia da escritura literária, e chegou mesmo a escrever que a busca fenomenológica "é laboriosa como a obra de Balzac, de Valéry ou de Cézanne" (2010, p. 20). Para Merleau-Ponty,

A verdadeira filosofia é reaprender a ver o mundo, e nesse sentido uma história narrada pode significar o mundo com tanta 'profundidade' quanto um tratado de filosofia. Nós tomamos em nossas mãos o nosso destino, tornamo-nos responsáveis, pela reflexão, por nossa história, mas também graças a uma decisão em que empenhamos nossa vida, e nos dois casos trata-se de um ato violento que se verifica exercendo-se (2010, p. 19).

O aporte fenomenológico será fundamental na continuação deste trabalho, no momento em que será preciso entender como aparece o que chamo de coexistência em duas das buscas de Robbe-Grillet em Les Gommes: um novo tratamento do tempo no romance e a investigação das possibilidades narrativas, das diferentes formas de se apreender um acontecimento no romance, desde distintas vozes.

\section{A coexistência no tempo do romance}

Não só para Robbe-Grillet a questão do tratamento do tempo no novo romance foi central; em Michel Butor, por exemplo, mais do que no autor de Les Gommes, tal 
experimentação perpassa toda a obra. Em O novo romance francês, Leyla PerroneMoysés coloca os dois autores em paralelo ao tratar a questão temporal. E afirma que, em Les Gommes, o que o leitor pode encontrar é um congelamento do tempo, uma narrativa com o eixo fixado no presente:

Mas, acima de tudo, o A. tem um desígnio técnico: a abolição do tempo no romance. Não é por acaso que o relógio do Inspetor Wallas para no instante culminante. Os futuros romances de Robbe-Grillet nos mostrarão que a sua intenção é imobilizar o tempo. Ao contrário de Butor, Grillet procura criar um tempo para assim dizer imóvel, um eterno agora, o presente imutável de um instantâneo fotográfico (1966, p. 53).

Não por acaso, a trama do romance de Robbe-Grillet se passa, por inteiro, ao longo de apenas um dia, uma larga terça-feira de início de inverno, e o que vemos, a partir do que o autor denomina de "Prólogo", e que apresenta as bases do romance, é a longa investigação-caminhada de Wallas pela cidade, às voltas com as pistas que não fecham e com a aparente incoerência dos suspeitos. Desde as primeiras horas da manhã, quando o inspetor se vê praticamente sozinho nas ruas, até o final do dia, quando um novo assassinato (ironicamente, da mesma vítima) acelera o desfecho da narrativa. Ainda que o narrador informe, uma e outra vez, o momento do dia em que determinada ação se passa, a sensação de um prolongado agora se mantém do início ao final, seja pela ausência de pausas significativas na narração, seja pela circularidade dos acontecimentos que não terminam por se resolver. Wallas, em diversos momentos, percebe que está novamente em frente ao prédio cuja soleira havia abandonado algumas páginas atrás.

É Urbano Tavares Rodrigues, na já mencionada introdução à edição portuguesa, que atenta para a relação entre o tratamento do tempo em Les Gommes e o problema dos objetos no romance. Para Rodrigues, a dimensão do tempo na obra se aproxima da que pode ser encontrada nos objetos - o tempo "da realidade bruta da vida, para além da dúvida", e que acaba por atordoar o homem: "através das recorrências que tornam presente o passado, quando as sensações banais se repetem ou quando o tempo modificou a situação das coisas precisas, inquietando o homem, surge o interesse maior dos romances de Alain Robbe-Grillet: a dimensão temporal dos objetos" (s.d., p.8). O ensaísta e escritor português, ele próprio tradutor do livro para a nossa língua, afirma que a questão temporal justifica também a tradução nada literal do título do romance: "quer lhe chamássemos As borrachas [a transposição direta do francês para o português de Les Gommes], quer lhe chamemos Entre dois tiros, em qualquer destes títulos avulta a personagem Tempo" (s.d., p. 07).

Desde a primeira página do romance, a passagem do tempo aparece como preocupação estilística e temática em Les Gommes. O romance tem início com a cena em que o proprietário de um café, que o leitor logo saberá tratar-se do Café dos Aliados, onde Wallas irá se hospedar na cidade, arruma as mesas e cadeiras do local para mais um dia de trabalho. Ainda anestesiado pelo sono e o frio da madrugada, o homem, um bronco e malhumorado patrão, age mecanicamente para impor sua ordem ao espaço. Assim, pode-se ler: 
leis antigas regulam os pormenores dos seus gestos, ocasionalmente salvos da flutuação das intenções humanas; cada segundo marca um movimento puro: um passo para o lado, a cadeira a trinta centímetros, três limpadelas com o esfregão, meia volta à direta, dois passos em frente, todos os segundos delimitados, perfeitos, iguais, sem mácula. Trinta e um. Trinta e dois. Trinta e três. Trinta e quatro. Trinta e cinco. Trinta e seis. Trinta e sete. Cada segundo no seu exato lugar (s.d., p. 13).

Na sequência da mesma página, o leitor irá se deparar como que com um aviso: "infelizmente o tempo deixará em breve de ser o supremo senhor". Os acontecimentos, conta o narrador, serão envolvidos por um círculo de "erro e dúvida", e logo deverão afetar a "ordem ideal", "introduzir aqui e além, traiçoeiramente, uma inversão, uma deslocação, uma confusão, uma curvatura, a fim de realizarem pouco e pouco a sua obra" (s.d., p. 13).

O círculo de "erro e dúvida", capaz de cercar a atmosfera do romance, encontra na repetição de descrições de relógios parados um dos seus elementos constitutivos. Metáfora de um prolongado presente, de um agora tensionado indefinidamente, de um instante que se congela, como que numa fotografia. Seja como for, tal recurso é utilizado uma e outra vez em passagenschave do romance. Primeiramente, podemos ler, no início da manhã de terçafeira, no momento em que o inspetor Wallas percebe que sente fome e que não havia tomado o café da manhã, como ele poderá saber apenas aproximadamente em qual momento do dia se está: o seu relógio parara de funcionar. "Olha maquinalmente para o relógio e verifica que ele não voltou a trabalhar; parou ontem à noite, às sete e meia, o que não facilitou as coisas para a viagem e para o resto. De vez em quando acontece-lhe parar, não se sabe bem porquê" (s.d., p. 48).

Páginas depois, no final do capítulo primeiro, a questão retorna ao texto: "Wallas relanceia o relógio de pulso: continua a marcar sete horas e meia. No quarto de Dupont, em cima do fogão, o relógio de bronze está igualmente parado, entre os candelabros sem velas" (s.d., p.98). O relógio de pulso e o de parede, o de bronze, apontam para um mesmo horário, e não se trata de um ponto casual no tempo da narrativa: como se pode saber desde muito cedo no romance, foi às sete horas e meia que o atirador disparou sua arma contra o professor Daniel Dupont, e é também nesta marcação do relógio que, supostamente, a série de estranhos assassinatos têm ocorrido em diferentes pontos do país. A mesma hora, paralisado instante, une Wallas e Dupont, o detetive e vítima. Mais do que isso, os ponteiros congelados indicam o centro do universo de Les Gommes, o ponto para o qual convergem as estruturas do texto - como esferas que vagam ao redor do acontecimento que é o crime, obsessivamente, sem, no entanto, o tocarem de todo. Quanto ao enredo, também se pode dizer que a indicação fixa de um momento preciso mostra que, desde o início, os esforços para desvendar o caso pouco puderam caminhar em direção ao desfecho do enigma.

A obsessão temporal também pode ser encontrada em outro plano da narrativa, menos visível que os elementos já citados, como o relógio parado e as menções a um presente contínuo. Trata-se de um tempo passado, de episódios anteriores ao tempo da narrativa e que ligam o inspetor Wallas àquela cidade. Em mais de um momento, o narrador informa, sem 
maiores comentários, que Wallas já esteve naquele lugar num passado distante, que corresponde à infância. Esteve e pode lembrar alguns lugares, a presença dos canais, e outra busca: encontrar alguém a que se veio visitar, na companhia da mãe, e em circunstâncias que a passagem do tempo nublou.

A primeira menção aparece ainda no capítulo primeiro, e revela pouco ou nada sobre as condições daquela já distante viagem:

chegou tarde, na véspera à noite, a esta cidade que mal conhece. Já cá veio uma vez, mas só por algumas horas, quando era criança, e não conserva dela uma recordação muito precisa. Ficou-lhe uma imagem de um pedaço de canal sem saída; a um dos cais está amarrado um velho barco fora de uso - uma carcassa [sic] de veleiro? Uma ponte de pedra, muito baixa, fecha a entrada. Talvez não fosse exactamente isso: o barco não teria podido passar por debaixo da ponte. Wallas retoma o seu caminho para o interior da cidade (s.d., p. 48).

Posteriormente, a viagem voltaria a ser objeto de preocupação de Wallas. Em um diálogo com uma habitante do lugar, certamente nativa, o inspetor deseja pedir informações sobre como chegar às ruas centrais para prosseguir com a caminhada e a investigação, mas teme que, ao mencionar os lugares que planeja visitar, tenha que discorrer sobre a primeira vez em que esteve ali:

certamente teria sido mais simples dizer logo àquela mulher que deseja percorrer as ruas principais da cidade onde vinha pela primeira vez; mas não seria levado, por escrúpulo, a falar da antiga viagem? As ruelas cheias de sol onde acompanhara a mãe, o pedaço de canal entre as casas baixas, o caso abandonado de navio, aquela parente (uma irmã da mãe ou uma meia irmã?), que deviam encontrar. Pareceria que vinha em busca de recordações da infância (s. d., p. 62).

A confusão, conforme a recordação da passagem de Wallas pela cidade ganha cada vez mais consistência, à medida que detalhes retornam sem cessar, também aumenta: e o temor do personagem, expresso pelo narrador na frase destacada do fragmento acima, pode revelar algo sobre o tempo da narrativa. Em Les Gommes, a descrição da viagem de infância aparece pela primeira vez no texto, como foi visto, em um registro veloz, sem força ou interesse destacado; depois, algo sobre as intenções da viagem se revela (acompanhar a mãe na busca por alguém, um familiar algo distante); e então, páginas adiante, o leitor saberá que a primeira viagem é, na verdade, uma busca que comporta tensões, a busca por uma herança, um percurso formado por perdas e desencontros:

Já uma vez vagueara no meio daquelas bifurcações imprevistas e daqueles becos sem saída, onde uma pessoa se perdia ainda mais facilmente quando conseguia andar a direito. Só a mãe é que se preocupava com isso. Tinham por fim chegado àquele canal fechado; as casas baixas, ao sol, miravam as suas velhas fachadas na água verde. Devia ser no Verão, durante as férias escolares: tinham ali parado (quando iam, como todos os anos, para a praia, mais ao Sul) a fim de visitarem uma parente. Julga lembrar-se de que esta se zangara, de que havia uma história ou qualquer coisa nesse gênero. Mas tê-lo-ia chegado a saber exactamente? (s.d., p. 137).

Pouco a pouco, o tempo passado, em um primeiro momento aparentemente 
irrelevante, nebulosa recordação, se aproxima do tempo presente, circunda-o, acabam os dois por se misturar e se justificar um ao outro. Logo outras informações se incorporam a esta parcela do relato: a pessoa que Wallas e a mãe procuram é, na verdade, o seu próprio pai, que por ali vivera; quanto às possíveis motivações para a morte de Daniel Dupont, um dos personagens supõe que pode ser relativo a um filho que retorna em busca da herança; e, ainda, o título original do romance e a incessante busca por borrachas nas papelarias da cidade aludem, de modo indireto, à necessidade de se apagar parte da história, de borrar um pedaço do passado que, apesar dos intentos de Wallas, teima em saltar ao plano primeiro da narrativa. Na sua introdução ao romance, Urbano Tavares Rodrigues observa, sem maior profundidade, que o personagem principal carrega consigo, "ao menos na sua inconfessa obsessão" (s.d., p. 08), o mito de Édipo.

Essa, no entanto, é tão somente uma possibilidade de leitura de Les Gommes (uma possibilidade mesmo no que diz respeito ao problema do tempo no texto, visto que essa abordagem também é múltipla), já que a busca de Wallas ocorre em distintas camadas - a subterrânea busca por uma lembrança de infância, que seria também uma busca pelo pai, coexiste à investigação do drama policial, às verdades que se perdem numa cidade labiríntica. Há, em Les Gommes, uma interessante menção ao alcance das verdades e à força inevitável das tentativas e das versões, isso quando Wallas se pergunta se as recordações que guarda daquela cidade não teriam, na verdade, origem no engano ou no sonho, e se as peças que se juntam para organizar a lembrança não seriam, por sua vez, peças falsas.
Assim, o tratamento do tempo se acomoda ao lado da questão das possibilidades narrativas, nas formas plurais de se contar a mesma história, de apreender um momento que, simultaneamente, é o mesmo e acaba por se modificar quando descrito por um ângulo novo ou uma nova voz. Em Les Gommes, coexistem os tempos, o hoje congelado e o passado que se transporta pouco a pouco para o momento presente, bem como coexistem as chances de narrar e apreender o real. Para Leyla Perrone-Moisés,

Toda a concepção romanesca dos novos-romancistas repousa no reconhecimento de que o campo do romance é o campo do possível. Daí nasce também uma nova concepção do campo romanesco. Seu desenrolar nunca é linear, mas enovelado, quadrimensional, reversível. O tempo passado é guardado na memória como um bloco compacto que pode ser ressuscitado por parte, sem levar em conta a ordem em que se deram os acontecimentos, mas respeitando simplesmente o mecanismo das associações, segundo o qual os fatos ressurgem e são mais ou menos ampliados segundo o eco que tiveram na sensibilidade do indivíduo (1966, p. 19, destaque meu).

Ao pensar o campo do romance como o "campo do possível", outra vez Les Gommes surge como importante exemplo (mais que isso: como ponto de partida) para as experimentações formais do que o novo romance francês levaria adiante.

\section{A coexistência das possibilidades narrativas no romance}

É Michel Butor, em Repertório, livro que reúne a primeira parte de seus ensaios, quem compara a insuficiência 
da realidade, na tentativa de oferecer a totalidade dos fatos, com a proposta do romance. Para Butor, mesmo as narrativas verídicas fracassam ao abarcar, por todos os lados e de todas as maneiras, um fato, uma informação, uma condição, um movimento. Restará, sempre, a chance da versão, o relato que simultaneamente escolhe e exclui, define um ponto de vista e deixa outros para trás.

Em Alain Robbe-Grillet, escritor que também levou a cabo uma importante obra ensaística, tida por alguns críticos como a base teórica do novo romance francês, existe a defesa de uma determinada forma de narrar uma história - e que adquire o caráter da descrição. Para o autor de Les Gommes, o texto romanesco e sua estrutura precisam estar em afinidade com o mundo em que se inserem, plano maior que não deixa as suas bases intactas, e que no momento da escritura se abre para uma modernidade plena de dúvidas. A isso, é preciso recordar a já mencionada proximidade com a fenomenologia: é nesta relação que se define um modo de ver o mundo, os objetos, os acontecimentos que, através da escrita literária, formam o tecido do romance. Para Maurice Merleau-Ponty, na Fenomenologia da percepção, o mundo real já está, mais firme e antigo que as divagações e juízos do seu observador. A saída pode estar em perceber para então descrever esse conjunto:

O real deve ser descrito, não construído ou constituído. Isso quer dizer que não posso assimilar a percepção às sínteses que são da ordem do juízo, dos atos ou da predicação. A cada momento, meu campo perceptivo é preenchido de reflexos, de estalidos, de impressões táteis fugazes que não posso ligar de maneira precisa ao contexto percebido e que, todavia, eu situo imediatamente no mundo, sem confundi-los nunca com minhas divagações (2010, p. 5).

Ao se afastar da construção antropocêntrica de um universo romanesco particular, resta ainda outro problema: como descrever este "real" de que fala Merleau-Ponty, como chegar perto das coisas, dos objetos e das situações que envolvem personagens humanos, no texto literário? O anseio de Merleau-Ponty avança no seu trabalho sobre a percepção, e o filósofo sugere que a saída pode estar na compreensão de que o pensamento ("a história", escreve Merleau-Ponty) é mais uma rede que uma linha, contempla diferentes chances de análise, um fundo comum, coexistência de fatores, de justificativas, de ângulos.

É emblemático o parágrafo em que o filósofo questiona o que perpassa um gesto aparentemente casual, um silêncio quem sabe desimportante, e nos quais sempre residirá algo do todo:

Eu acreditava ter-me calado por fadiga, tal ministro acreditava só ter dito uma frase de circunstância, e eis que meu silêncio ou sua fala adquirem um sentido, porque minha fadiga ou o recurso a uma frase feita não são fortuitos, eles exprimem certo desinteresse e, portanto, certa tomada de posição em relação à situação. Em um acontecimento de perto, no momento em que é vivido, tudo parece caminhar ao acaso: a ambição deste, tal encontro favorável, tal circunstância local parecem ter sido decisivos. Mas os acasos se compensam e eis que essa poeira de fatos se aglomera, desenha certa maneira de tomar posição a respeito da situação humana, desenha um acontecimento cujos contornos são definidos e do qual se pode falar. Deve-se compreender a história a partir da ideologia, ou a partir da política, ou a partir da religião, ou 
então a partir da economia? Deve-se compreender uma doutrina por seu conteúdo manifesto ou pela psicologia do autor e pelos acontecimentos da sua vida? Deve-se compreender de todas as maneiras ao mesmo tempo, tudo tem um sentido, nós reencontramos sob todos os aspectos a mesma estrutura de ser. Todas essas visões são verdadeiras, sob a condição de que não as isolemos, de que caminhemos até o fundo da história e encontremos o núcleo único de significação existencial que se explicita em cada perspectiva (2010, p. 17, destaque meu).

"Todas essas visões são verdadeiras": eis um fragmento do discurso de MerleauPonty que podemos transpor para a tentativa de compreender a construção literária de Les Gommes, principalmente no que se relaciona com as possibilidades do romance, a coexistência dos planos da narrativa. Les Gommes é, então, um romance que não se fecha; as indefinições preenchem mais de uma circunstância.

Ainda no capítulo primeiro, quando o inspetor Wallas se encontra com o comissário Laurent, responsável pelas investigações da cidade, mas que permanece à margem do caso de Daniel Dupont, o segundo homem aponta que algumas inconsistências no relato de Wallas podem comprometer a ordem das coisas. Irônico, em um primeiro momento, mas disposto a prosseguir com a provocação, Laurent mostra que, no estranho episódio da Rua dos Agrimensores, o detetive em questão pode ocupar também outro lugar na história: o de assassino. Isso porque o inspetor chegou à cidade na noite do assassinato, está hospedado num questionável café que aluga quartos, e cujo registro não consta nos cadernos policiais, além de portar um revólver cujo carregador está com um projétil a menos.
O leitor pode acompanhar o diálogo entre Wallas e Laurent:

- Suponha que o assassino lá dormiu ontem. Como poderá o senhor sabê-lo? - O hoteleiro ter-me-ia feito a sua declaração, como vai fazer a sua daqui a pouco tempo. E até ao meio-dia.

- E se ele a não fizer?

- Muito bem: nesse caso, teria que me inclinar perante o seu faro, por ter descoberto tão depressa o único covil clandestino da cidade. Vendo bem, seria mesmo mau para si; seria o meu amigo, em suma, o primeiro suspeito sério que encontro: chegando de fresca na cena do crime, e tudo isto às escondidas da polícia (s.d., p. 79).

Com o passar das páginas, a situação do caso se enreda ainda mais numa teia de espelhismos, casualidades, coexistências. Wallas será confundido com um homem de sobretudo que vai aos correios depositar telegramas, considerado um dos suspeitos do crime; Albert Dupont, um rico industriário da cidade, com quem os jornais confundem Daniel Dupont no início da narrativa, acaba assassinado na noite seguinte, num erro que se corrige fatalmente.

E, por fim, e eis o mais significativo acontecimento da obra, ao final o próprio Wallas, supostamente contra a sua vontade, e imerso no mesmo círculo "de dúvida e erro" que o narrador anuncia no prólogo, leva adiante o assassinato até então incompleto de Daniel Dupont. Wallas volta ao pavilhão da Rua dos Agrimensores, com a expectativa de que irá se encontrar, por volta das sete e meia da noite, com o assassino que retorna à cena do crime. $\mathrm{Na}$ mesma hora, Daniel Dupont, a vítima da véspera, retorna a sua casa, depois de horas escondidos na clínica do doutor Juard, para buscar os seus papéis e abandonar a cidade. 
A farsa do assassinato que não ocorreu poderia então triunfar. Mas o encontro entre Wallas e Dupont, um encontro na hora congelada de Robbe-Grillet, amplia o desencontro para a tragédia e o riso. $\mathrm{O}$ assassinato pendente, agora, pelas vias mais tortas, seria confirmado, e Wallas irá disparar a arma.

Wallas é o assassino e não é; Garinati, o responsável pelo disparo inicial, está na mesma situação. Esse mesmo Garinati, em diálogo com Jean Bonaventure, o responsável por encaminhar o crime e designar quem o executaria, recebe o afago do chefe. Ao que parece, apesar do disparo sem direção, Daniel Dupont estava morto - e isso vale mais do que as circunstâncias do acontecimento:

- É com certeza um erro - diz Garinati.

- Só o feri.

- Ele morreu. Tem sorte.

- Talvez o jornal se engane?

- Sossegue; tenho os meus informadores privados. O Daniel Dupont morreu só com um pouco de atraso, afinal de contas.

Depois de uma pausa, Bona acrescenta com menos secura:

- Sempre foste tu que o mataste.

Como se atira um osso a um cão (s. d., p. 104).

É possível que Wallas e Garinati tenham assassinado Daniel Dupont; que Albert Dupont tenha sido morto por engano; que a busca por Wallas na cidade não tenha sido apenas a caminhada investigativa, mas um retorno a um episódio de infância que ainda precisa solucionar; que a geografia desta cidade repleta de canais, pontes levadiças e boulevards circulares confunda de fato o caminhante, levando-o ao erro e à ambiguidade; que cada fragmento de episódio tenha sido pensado, desde o começo, pela organização terrorista responsável pelos crimes. Tais possibilidades coexistem, todas elas, e ao final da leitura os movimentos parecem tão falsos como verdadeiros. Em Les Gommes, a intrincada composição do enredo está a serviço de uma percepção específica do mundo, alinhada com o pensamento fenomenológico, e de uma profunda experimentação formal; romance voltado sobre si mesmo, sobre suas chances e seu inevitável limite.

\section{Referências}

BUTOR, Michel. Repertório. São Paulo: Perspectiva, 1974.

MERLEAU-PONTY, Maurice. Fenomenologia da percepção. São Paulo: Martins Fontes, 2010.

PERRONE-MOISÉS, Leyla. O novo romance francês. São Paulo: Buriti, 1966.

ROBBE-GRILLET, Alain. Entre dois tiros. Lisboa: Livros do Brasil, [s.d.]. . Por um novo romance. São Paulo: Documentos, 1969.

Recebido: 15 de junho de 2017. Aceite: 19 de agosto de 2017. 